\title{
Termitomyces Species from Tanzania, Their Cultural Properties and Unequalled Basidiospores
}

\author{
Donatha Damian Tibuhwa \\ Department of Molecular Biology and Biotechnology, University of Dar es Salaam, \\ P.O. Box 35179, Dar es Salaam, Tanzania
}

Tel: 255-22-241-0501-08 ext. 2147. E-mail: dtibuhwa@yahoo.co.uk

Received: April 17, 2012 Accepted: May 11, 2012

doi:10.5296/jbls.v3i1.1723 URL: http://dx.doi.org/10.5296/jbls.v3i1.1723

\begin{abstract}
Termitomyces R. Heim, a basidiomycete fungus lives in a mutualistic symbiosis with termites of the subfamily Macrotermitinae. This study explored the cultural properties and macro-micromorphological characters including scanning electron microscopic studies of ten Termitomyces species collected from different parts of Tanzania. Pure cultures were isolated from the asexual fruit bodies growing on or near the termite mound by tissue culture techniques in three different media Ghosh, Hagem Modess, and Modified Malt Extract Agar. The results showed that Termitomyces aurantiacus (Heim) Heim and Termitomyces striatus Heim have unsmooth basidiospore, the character noted for the first time in this genus, and the two species might be conspecific. In cultures, while micromorphological characters remain undistinguishable between taxa, Macromorphological characters distinguished them in colour of the mat, growth rate, mycelia elevation and advancing zones as well as the mat texture. $T$. saggitiformis (Kalchbr. \& Cooke) D.A. Reid, T. titanicus Pegler \& Piearce species are reported for the first time in the country record and key to the studied species is supplied. This study suggests the redefining of the genus by omitting the smooth or adding unsmooth basidiospore character in the genus circumscription.
\end{abstract}

Keywords: Termitomyces, Conidia, Sporodochia, Taxonomy, Tricholomataceae 


\section{Introduction}

Termitomyces R. Heim is a paleotropical genus of agarics obligatory symbiotic with termites belonging to the subfamily Macrotermitinae (Isoptera). Their geographical distribution coincides with distribution of termites exclusively found in Africa and some parts of South East Asia. The Macrotermitine termitest belonging to the Termitidae subfamily that includes the genera Odontotermes, Microtermes, Macrotermes, Hypotermes, Protermes and Canthotermes (Chang and Quimio 1982). Termitomyces species are usually characterised by the termite association, pinkish spore print, smooth basidiospores, prominent perforatorium on the pileus and the subterranean pseudorhiza connected to the comb in the termite nest (Heim 1977, Frøslev et al. 2003). They form a monophyletic clade in Agaricales based on molecular phylogenetic analyses (Moncalvo et al. 2000, Aanen et al. 2002, Rouland-Lefevre et al. 2002), although they genetically show geographic differentiation between Asia and Africa (Frøslev et al. 2003). The symbiont termites have a great impact on plant litter decomposition and carbon cycling in tropical ecosystems (Wood et al. 1989; Yamada et al. 2005). For example, Buxton (1981) demonstrated that fungus-growing termites consumed $90 \%$ of the dry woody litter in an arid tropical area of Kenya.

Termitomyces do not exist outside the termite nest, except in the guts of the termite and in the forms of basidiomes developing from the nest (Sands, 1960). Fungus-growing termites cultivate symbiotic fungi in their nest on a special substrate composed of dead plant material known as the fungus comb or fungus garden. The fungus produces small nodules, which are consumed by the termites along with the degraded comb. During rainy periods, the fungal mycelium of the termite combs produces mushrooms, which penetrate the termite nests and soil to spread their spores (Heim 1977, Frøslev et al., 2003).

In most Macrotermes species, termite workers ingest dead plant material and deposit undigested or partially digested faeces on the top rim of the fungus comb. Several roles of symbiotic fungi have been proposed, including the provision of glycosyl hydrolases Martin and Martin (1978), enrichment of nitrogen (Collins, 1983; Matsumoto, 1976) and lignin degradation (Grassé and Noirot, 1958 ; Rohrmann, 1978; Hyodo et al., 2003) with the significance of each role apparently varying in importance among host termite species (Rouland, 2000; Hyodo et al., 2003). Because of the complex character of their ecosystem, presently no one has succeeded in domesticating these mushrooms.

The knowledge of Termitomyces is greatly due to Heim (1942) who gave the name to the genus and described 17 species in it from Africa and Asia. His work on the description of the genus and species is summarised in his book 'Termite Et Champgnon' (1977). Others who studied species of Termitomyces include: Otieno (1964), reported on 15 species from East Africa including five new ones; Alasoadura (1966), studied 6 species from Nigeria; Pegler (1977); Pegler and Rayner (1969), reported on 11 species from East Africa and Moriss (1986) reported on 8 species from Malawi. Pegler and Piearce (1980) and Piearce (1987) reported on 11 species including a new species T. titanicus Pegl. \& Piearce from Zambia; Buyck (1994) reported on 5 species from Burundi; Vander Westhuisen \& Eicker (1990) studied 7 species from South Africa including new three species and Botha and Eicker (1991) studied 5 species from South Africa in cultures. From Asia, Pegler and Vanhaecke (1994) studied 12 species from South East; Natarajan 
(1979) described a new species T. heimii Natarajan from India and Zhang and Ruan (1986) described two new species in the new genus Sinotermitomyces Zhang from China. Gómes (1995) described five new species from South America, which are all closely related to T. microcarpus (Berk. \& Broome) Heim and were previously described by Singer (1986) in the genus Podabrella and Tibuhwa et al. (2010) who summarised the utility of macro-micromorphological characters used in demarcating the species of Termitomyces the study which involved 25 species.

Culture studies of the genus Termitomyces Heim have been conducted on mycelium from comb sporodochia (see Petch, 1913; Batra and Batra, 1979; Heim, 1977; Piearce, 1987), while cultures from basidiome context fruit bodies have been done by Heim (1977); Piearce (1987) and Botha and Eicker (1991) who also confirmed cultural similarity of species from Asia and Africa. Recently, cultures on the species of the genus have been also done from basidiospore prints of $T$. microcarpus of the Lake Victoria basin by Olila et al. (2007).

In Tanzania the knowledge of Termitomyces is limited to Härkönen et al. (1995, 2003) who identified for the first time 5 species from the country including a new described species $T$. singidensis Saarim. \& Härk. Studies were done using macromorphological characters and light microscope observable microscopic characters. It is well known that microscopically, however, Termitomyces species are generally difficult to separate Frøslev et al. (2003), with many characters being the same and size overlaps. This thus envisaged this study to explore cultural properties in addition, as well as microscopic characters observed by Scanning Electron Microscopy (SEM). This work therefore describe ten Termitomyces species from Tanzania associated with Odontotermes species using macromorphology, micromorphology including Scanning Electron Microscopic features as well as culture characteristics of Termitomyces umkowaani and Termitomyces aurantiacus collected from Tanzania.

\section{Materials and Methods}

\subsection{Field Collection, Identification and Preservation}

The specimens were collected on or near the termite mounds located in different parts of Tanzania including Dar es Salaam region (Tabata, and University of Dar es Salaam main campus); Coast region (Kisarawe), Morogoro region (Ubena zomozi), Mara region in Mugumu district, Serengeti district including the Serengeti National Park, Kigoma region, Mtwara and Tabora region (Figure 1). They were found growing in troops, gregarious and singly-few fruitbodies. Identification of the specimen started from the field by comparing with already published work including Heim (1977), Buyck (1994), Morris (1986), Piearce (1987), Pegler and Van haecke (1994), Härkönen et al. (2003), then followed by microscopic investigations for species conformity. Collected fruitbodies after picking some for tissue culture were preserved for further studies by salt drenching while some were dried on oven (STOCKLI CH-8754, SWITZERLAND) at $50^{\circ} \mathrm{C}$ for 8 hours and preserved for later microscopic studies. Isolates of all studied species were deposited at the mycological herbarium of the "Museum National d' Histoire Naturelle Cryptogamie" at Paris (PC) and duplicates at the University of Dar es Salaam (UDSM). Termites were collected and their identities were determined by entomologist from the Department of Zoology University of Dar es Salaam. 


\section{Macrothink}

\subsection{Light and Scanning Electron Microscopy Investigations}

\subsubsection{Light Microscopy}

Size ranges of at least 20 randomly measured basidiospores, basidia, and cystidia were obtained using an ocular micrometer, computed statistically and recorded as explained in Tibuhwa et al. (2008). Pilei surfaces and hymeneal cells were also observed and the presence of any informative characters.

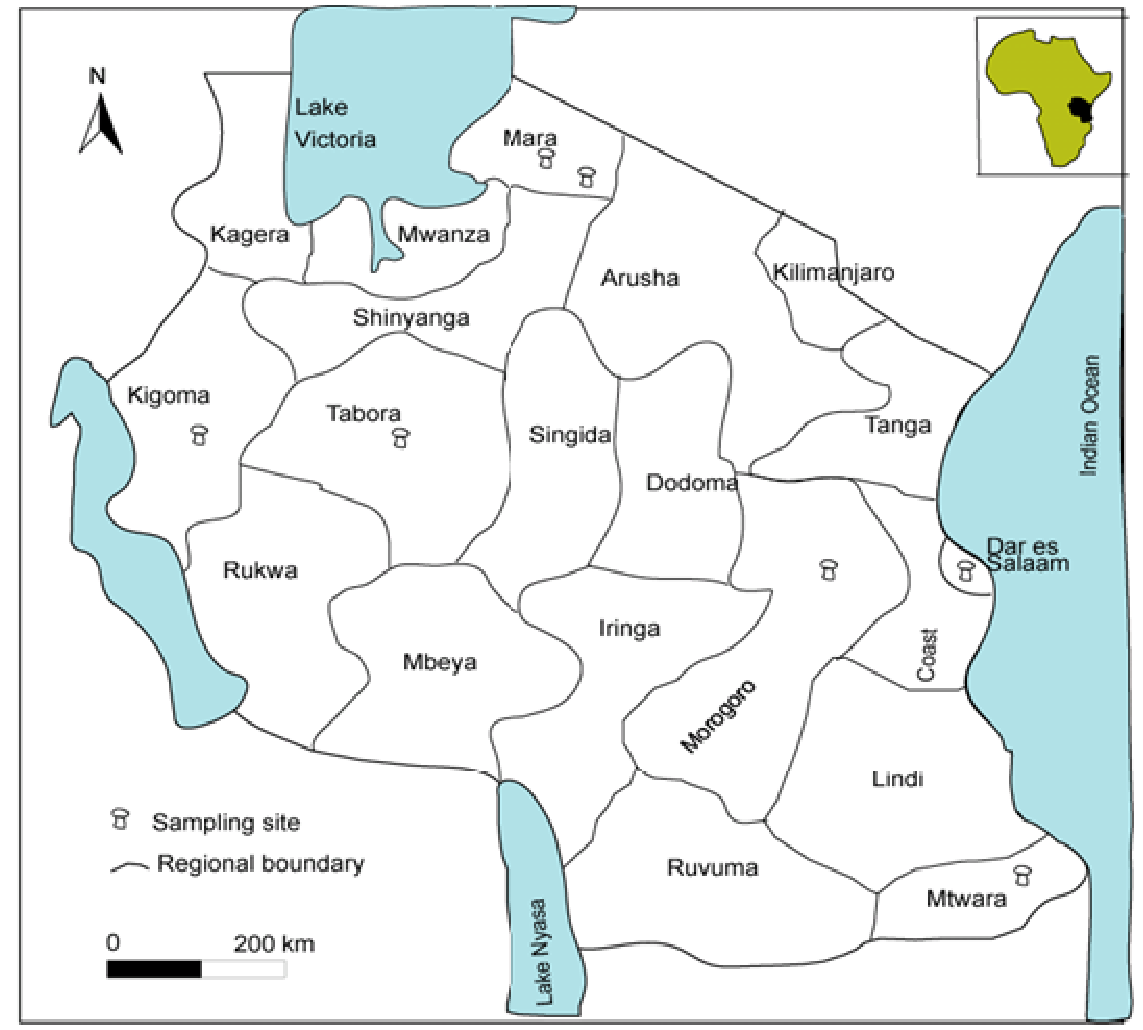

Figure 1. Tanzania map showing the sampling sites

\subsubsection{Scanning Electron Microscopy (SEM)}

Involved tissues of gill edge from dried specimen in which the spores and cystidia were observed and photographed, also cultures, termites and the termite comb. All materials were prepared in the same way as follows: From the gill edge, and other parts of the relevant specimen, small tissue and pieces were cut using sharp razorblade and fine forceps placed in a white tissue paper with fine pores of about 20 micrometer to allow liquid through, clearly labelled with a number which correspond exactly to the collection number of the specimen. The same procedure was done to all specimen scanned except for cultures which required a special mark to show clearly which side is up and down. Mycelia was scrubbed from the culture plate a process which was carried out in the laminar flow hood to avoid contamination and only the upper layer was scrubbed with little agar. Old portion from culture centre and the young portion from the periphery were examined for comparison purposes.

Preparation of fragments for SEM studies involved three important pre-treatment processes in order to make them not change with environmental fluctuations. The first step was 'quick drying' 
the process involved replacing all water from inside the cell by using alcohol. This was achieved through immersing the metal container with specimen in the alcohol of different dilutions for twelve hours, starting with $0 \%, 30 \%, 50 \%, 70 \%, 90 \%$, and $95 \%$ to $100 \%$. Second step was 'replacing the alcohol from the cell with carbon dioxide gas'. This process was done in the gas-compressing machine under very high pressure. The process was repeated three times in order to ensure that all the alcohol were completely replaced. The third step was 'gold plating the sample' The process was carried out in a gold film chamber where the film of gold was smeared on top of the sample to prohibit them from changing with environmental variation especially relative humidity thus stable in morphology and pattern. Specimens were examined in JSM-840 and No. 1EPSM 846-2S canning microscope.

\subsection{Tissue Culture}

Culture in this study started from a living mushroom fruit body by tissue culture method previously described by Stamets and Chilton (1983). Tissues were from the ten identified species, T. aurantiacus Heim, T. clypeatus Heim, T. eurhizus (Berk.) R. Heim, T. letestui (Pat.) R. Heim, T. microcarpus Berk \& Br., T. saggitiformis (Kalchbr. \& Cooke) D.A. Reid, T. striatus (Beeli) R. Heim, T. titanicus Pegler \& Piearce and T. umkowaani Cke \& Mass, Termitomyces mammiformis R. Heim but only two T. aurantiacus and T. umkowaani were able to grow. Fresh fruiting body were collected from the field and brought to the laboratory. Aseptically inner part of young fruit bodies were inoculated in three different synthetic media. For comparison purposes three different types of media were used for culture: (i) Ghosh et al. (1978) media: consists the following composition in 100g/liter. Dextrin 10; $\mathrm{NH}_{4} \mathrm{H}_{2} \mathrm{PO}_{4} 2.463$; boric acid 0.057; $\mathrm{K}_{2} \mathrm{PO}_{4} 0.087 ; \mathrm{MgSO}_{4} 7 \mathrm{H}_{2} \mathrm{O} 0.05 ; \mathrm{FeSO}_{4} 7 \mathrm{H}_{2} \mathrm{O} 0.025 ; \mathrm{Mncl}_{2} 4 \mathrm{H}_{2} \mathrm{O} 0.0036$; $\mathrm{NaMoO}_{4} 4 \mathrm{H}_{2} \mathrm{O} 0.0032 ; \mathrm{ZnSO}_{4} 7 \mathrm{H}_{2} \mathrm{O} 0.03 ; \mathrm{Cacl}_{2} 2 \mathrm{H}_{2} \mathrm{O} 0.037 \mathrm{pH} 2.5$. (ii) Modified Malt Extract Agar media (MMEA): In this media, the normal Malt Extract Agar (MEA) media was modified by adding some organic salts which are known to be found in the termite comb (Ghosh et al., 1978), such that the general composition of the media were MEA plus Boric acid 0.057; $\mathrm{K}_{2} \mathrm{PO}_{4}$ 0.087; $\mathrm{MgSO}_{4} 7 \mathrm{H}_{2} \mathrm{O} 0.05 ; \mathrm{FeSO}_{4} 7 \mathrm{H}_{2} \mathrm{O} 0.025 ; \mathrm{Mncl}_{2} 4 \mathrm{H}_{2} \mathrm{O} 0.0036 ; \mathrm{NaMoO}_{4} 4 \mathrm{H}_{2} \mathrm{O} 0.0032 ;$ $\mathrm{ZnSO}_{4} 7 \mathrm{H}_{2} \mathrm{O}$ 0.03; $\mathrm{Cacl}_{2} 2 \mathrm{H}_{2} \mathrm{O}$ 0.037. (iii) Hagem Modess media: This media composed of the following compositions: $\left(\mathrm{K}_{2} \mathrm{PO}_{4}, 0.5 \mathrm{~g} ; \mathrm{MgSO}_{4} . \mathrm{H}_{2} \mathrm{O}, 0.5 \mathrm{~g} ; \mathrm{NH}_{4} \mathrm{Cl}, 0.5 \mathrm{~g} ; \mathrm{Fe} \mathrm{Cl}_{3} 1 \%, 10\right.$ (drops); glucose, $5.0 \mathrm{~g}$; distilled water, 1liter). Incubation was done in the incubator and maintained at constant temperature of $30^{\circ} \mathrm{C}$ for 12 weeks where the colony diameter was recorded every week.

\section{Results and Discussion}

\subsection{Studied Taxa}

Ten species of Termitomyces were identified and studied together with herbarium specimen from the National herbarium Cryptogamie Paris (PC). Combined macromi-cromorphological characters including the Scanning electron microscopic studies demarcated the species and suggested molecular characterization to the two pairs of taxa which might be conspecific $T$. aurantiacus vs $T$. striatus and $T$. umkowaani vs $T$. eurrhizus. Comments on the field identification of the studied taxa categorized them in three broad groups' small sized, medium, and large sized basidiome (see Tibuhwa et al., 2010). All the ten species known by different 


\section{Macrothink}

ethnic groups in different dialectics summarized in Table 1 are edible and well liked appreciated for their delicacy comparable to meet Buyck and Nzigidahera (1995).

\subsubsection{Temitomyces clypeatus Heim (Fig. 2)}

Iconography Piearce (1987: fig. 1); Vander Westhuisen \& Eicker, (1990: figs. 7-10); Heim, (1977: Pl. 1, Fig. 2, c, d and e); Härkönen et al. (2003, fig 113). Pegler and Rayner (1969: fig. 2/1 a-c); (1977: fig. 59/2 a-d).

Comments: The species is a small sized-to rarely medium sized mushroom. It is easily distinguished in the field by smooth blackish brown spinform perforatorium, silky greyish brown to ash grey cap with pale cracking margin, spirally twisted stipe narrowing to short pseudorhiza enlarging at the base. It is close to T. tyleranus, the noteworthy characters of $T$. clypeatus, however, are the slightly swollen black pseudorhiza and comparatively darker. The mushrooms are found growing in small groups around the termite mound especially in cleared fields.

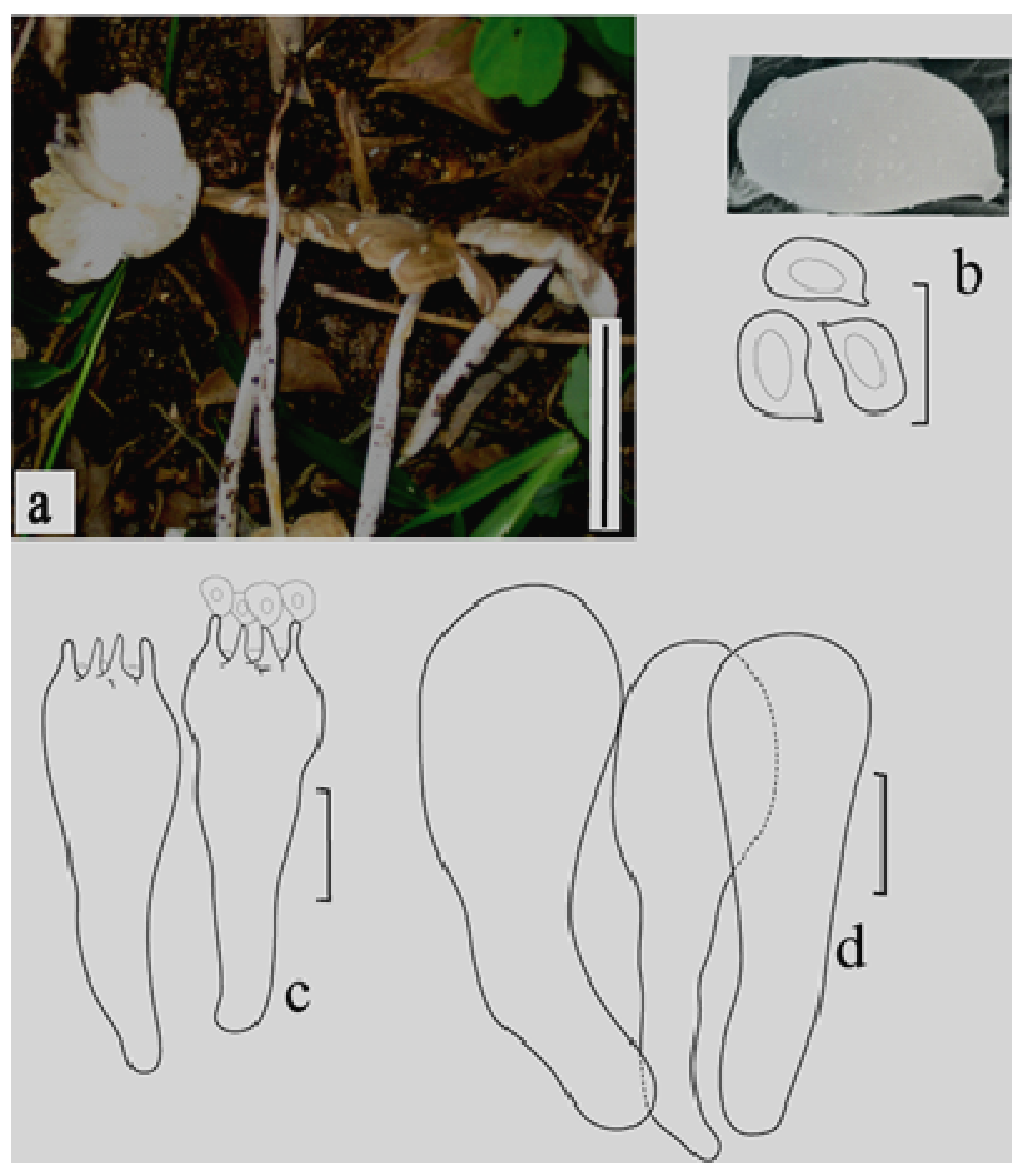

Figure 2. Termitomyces clypeatus (a) basidiome (b) basidiospore (c) basidia (d) cystidia

$$
\text { Represent } 10 \mu \mathrm{m} \text {; }
$$

Represent $10 \mathrm{~cm}$

Specimen examined: Tanzania Dar es Salaam Kinondoni - Univesity of Dar main campus opposite to the Faculty of Science DT2000-2 (UDSM), Ubenazomozi near the bridge which separate Pwani and Dar es Salaam regions DT2000-12 (UDSM) and Buyck (PC) 6293. 


\subsubsection{Termitomyces umkowaani Cke \& Mass. (Fig.3)}

Iconography Vander Westhuisen \& Eicker, (1990: figs 34-41), Tibuhwa et al. (2010: Fig 3d)

Comments: This species is among the large sized cap Termitomyces mushroom. Its gray colour marked with brown perforatorium which distinguish it easily in the field. It is demarcated from the close species T. eurrhizus by two microscopic characters the shape of cystidia and Basidiospore size. While T. umkowaani has broadly clavate to pyriform cystidia and somewhat large basidiospores Vander Westhuisen \& Eicker (1990) while T. eurhizus has obovoid to pyriform cystidia and relatively small basidiospores (Pegler and Van haecke 1994).

\begin{tabular}{|c|c|c|c|c|c|c|c|c|c|}
\hline \multirow{3}{*}{$\begin{array}{l}\text { Species } \\
\text { Termitomyces clypeatus }\end{array}$} & \multicolumn{9}{|c|}{ Venacular name } \\
\hline & Hehe & Ngoni & Nyambo & Kurya & Masai & Sukuma & Sambaa & Bena & Swahili \\
\hline & Widungu & Vidungwe & Bunyamuswa & vihungum & ururyo & Busolele & Ungala & Vigon'gongo & Uyogamchwa \\
\hline T. umkowaani & Vidungwe & Ungala & Chinyanchonjo & Mughu & & lyobha & & Widungu & Uyogamchwa \\
\hline T. aurantiacus & Vidungwe & Ungala & Bunyantuku & vihungum & ururyo & & Madondo & & Uyogamchwa \\
\hline T. striatus & Vidungwe & Ungala & Bunyantuku & vihungum & Ormambuli & & Madondo & & Uyogamchwa \\
\hline T. saggitiformis & & & & Mughu & Ormambuli & mobha & & Vigon'gongo & Uyogamchwa \\
\hline T. mammiformis & Unyakigulu & Vidungwe & Bunyamuswa & Bhitoghos & & Bumegele & e Ungala & Vigon'gongo & Uyogamchwa \\
\hline T. titanicus & & & Mpefu & Lyugu & Ormambuli & Lyobha & & & Uyogamchwa mkubwa \\
\hline T. microcarpus & Unyafigulu & & Butuzi & Bitoghose & Ormambuli & Bumegere & & Unyonso & Uyogamchwa mdogo \\
\hline T. letestui & Wikulwe & Vitundwi & Nyamkundi & Lyugu & Ormambuli & Lyobha & Kitundwi & Wikule,Wikulu & Uyogamchwa mkubwa \\
\hline T. errhizus & Chova & Ungala & Chinyamkundi & Lyugu & & Lyobha & & & Uyogamchwa \\
\hline
\end{tabular}

In close observations from the literature there is lack of consistency in the size of the basdiospores and clear size overlaps between the two species. This study thus second the suggestion by Tibuhwa et al. (2010) of carrying out a scientific review especially the use of molecular markers to ascertain the taxonomic status of the two species. The SEM results on the basidiospores revealed it to have young 1-2 sterigmata actuate it to have sometime untetra basidospores (see Tibuhwa et al., 2010).

\subsubsection{Termite and Termite Comb}

T. umkowaani was found growing in the garden on the termite mound, its pseudorhiza extended downward to a termite comb (Fig. 8 a). The comb is a sponge like in appearance with dots of white stuffs 'sporodochia' scattered over the surface. It is made of small spheres of plant material quickly passed through the termite gut. Examination of termite comb on the SEM showed clearly the sporodochia developing on the surface of the comb with the extension of the mycelia penetrating the foraged matter within the comb (Fig. 8 b). A piece of sporodochia observed on the high power microscope with a camera lucida, showed the sporodochia be made of big cells like those found in the culture enlarged one (see Figs 8d and f), which later differentiate to form conidia. 


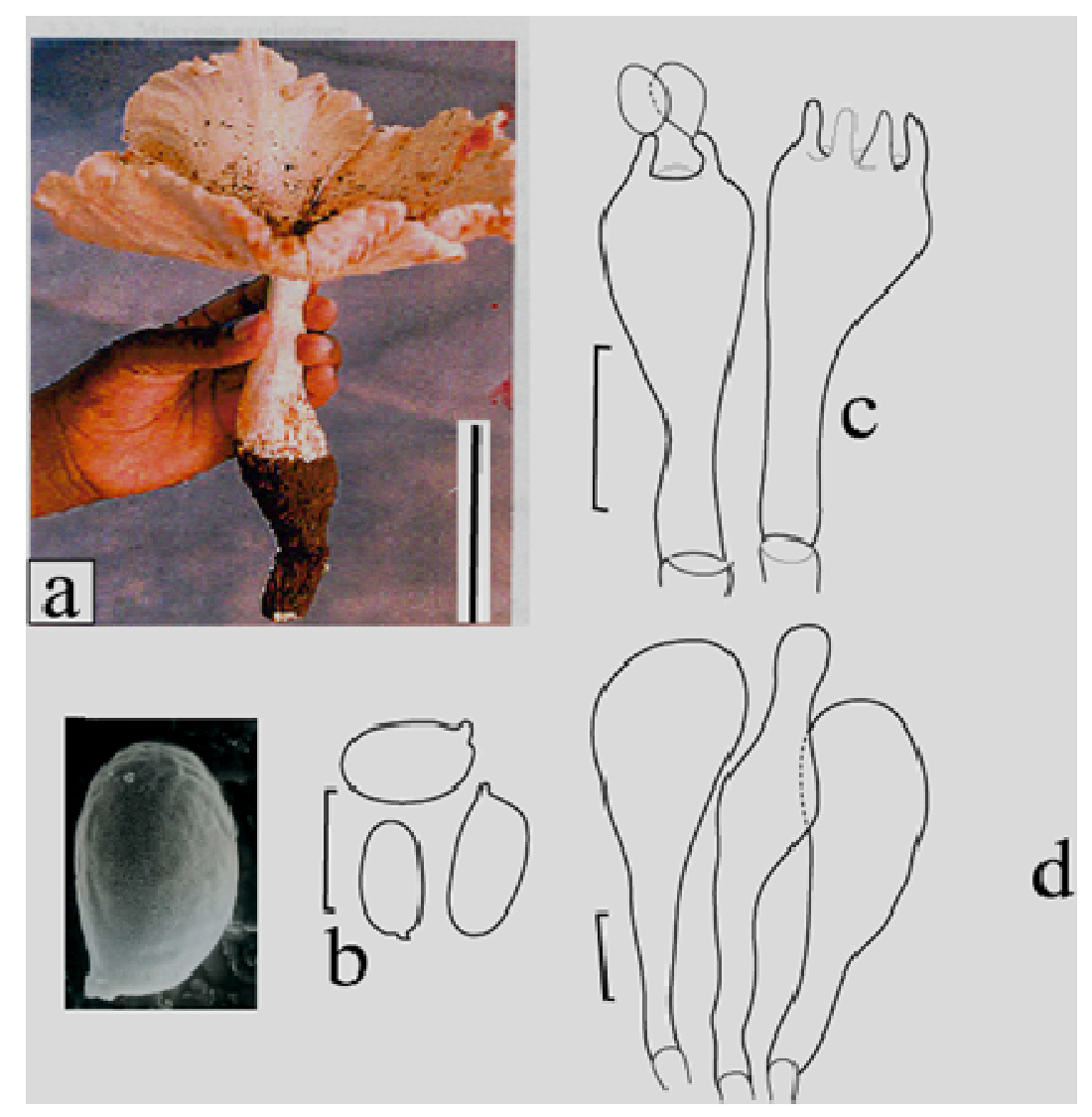

Figure 3. Termitomyces umkowaani (a) basidiome (b) basidiospore (c) basidia (d) cystidia
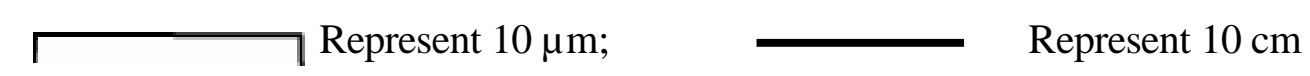

Conidia are asexual spore which sporulate and differentiate to form mycelia, young stages of mushroom, which germinate to fruit bodies when the environmental conditions are conducive mostly during the rain season. Odontotermes badius (Fig. 8e) was the identified termite symbiont with all studied species except $T$. microcarpus which was also found to associate with Odontotermes vulgaris.

Specimen examined: Tanzania Dar es Salaam Kinondoni - Tabata D2000-6 (UDSM); Tabata D 2001-2; Kinondoni - Kawe D2001-12 (UDSM); Buyck (PC) 6292

\subsubsection{Termitomyces aurantiacus (Heim) Heim (Fig.4)}

Iconography Härkönen et al. (1995: fig. 42); Pegler \& Vanhaecke (1994: fig. 4); Heim (1977: fig. 10); Tibuhwa (2010: fig 3b).

Comments: T. aurantiacus is a medium sized mushroom found growing scattered in the cleared field and open woodland (Tibuhwa et al., 2011) occupied by termites especially during early rains. T. aurantiacus resemble T. striatus (Fig. 5) in the field and they are known to be demarcated by the bright ochraceous yellow colour of T. aurantiacus compare to the ochraceous brown of $T$. striatus and its variety. SEM study of both taxa revealed them to posse's unsmooth basidospore (Figs $4 \mathrm{~b}$ and 5b). Termitomyces species are known for 


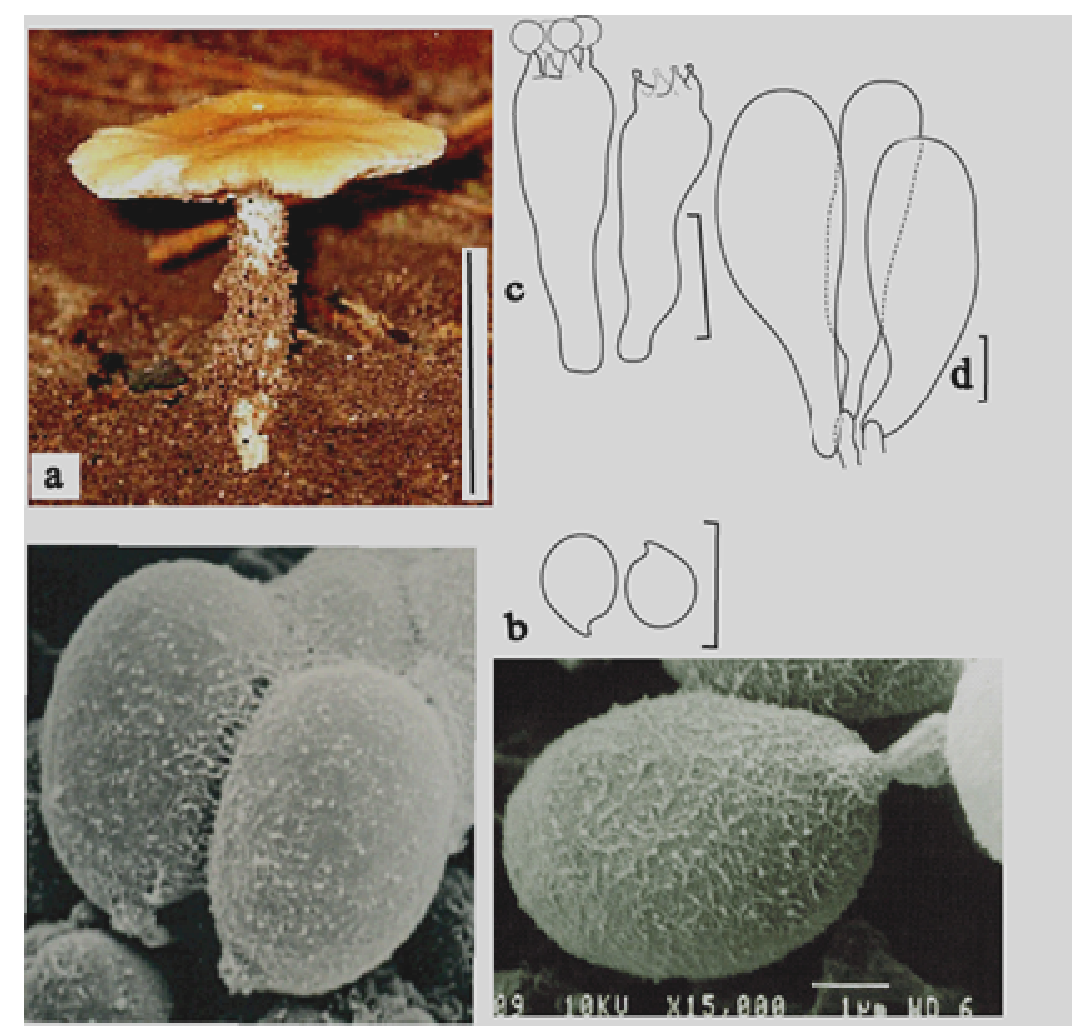

Figure 4. Termitomyces aurantiacus (a) basidiome, (b) basidiospore unsmooth surface revealed in SEM, (c) basidia (d) cystidia

\section{Represent $10 \mu \mathrm{m}$;}

Represent $10 \mathrm{~cm}$

having smooth basidiospores (Heim, 1942; 1977; Bels and Pataragetvit, 1982; Singer, 1986), however, the unsmooth basidiospores (covered by fine tufts) noted in T. aurantiacus and the isotype of T. striatus from PC was exceptional noted for the first time in this genus. Moreover sharing of this unique character, beefs up the possibility of them being conspecific. They resemble in general descriptions of the stipe and pseudorhiza and possession of irregular moniliform cells below the epicutis. Basidioma colour is not a good distinguishing trait for these closely related species since different forms of colour have been observed in T. striatus like pale grayish to grayish-brown found by Vander Westhuisen \& Eicker (1990), ochraceous brown by Heim (1977), grayish brown by Pegler \& Vanhaecke (1994) and ochraceous brown to rust brown by Buyck (1994). This outstanding difference is further deterred by the fact that type of the soil or substrate and nutritional status of the comb affects the sporocarp colour (Piearce, 1987).

Formally Heim (1942) described them as one species before he changed his mind in (1977) and separated them into two species. Several varieties of T. striatus were later described by Heim basing on annulated stipe and colour. The annulated type is T. striatus (Beeli) Heim f. annulatus Heim. Two non annulated variety based on colour are T. striatus (Beeli) Heim f. ochraceus Heim and T. striatus (Beeli) Heim f. griseus Heim.

Specimen examined: T. aurantiacus Tanzania Pwani- Kisarawe near Kazimzumbwi forest reserve D2000- 3; DT 20010-50 from Loliondo, Serengeti Mara region, DT 20011-14 from Mtwara; Buyck (PC) 96202, 


\section{Macrothink}

\subsubsection{Termitomyces striatus Heim (Fig.5)}

Iconography: Piearce (1987: figs. 1); Vander Westhuisen \& Eicker, (1990: figs. 11-15); Buyck (1994 Fig 20); Heim, (1977: Pl. 1, Fig. 1, a and b); Tibuhwa et al. (2010: fig 3c)

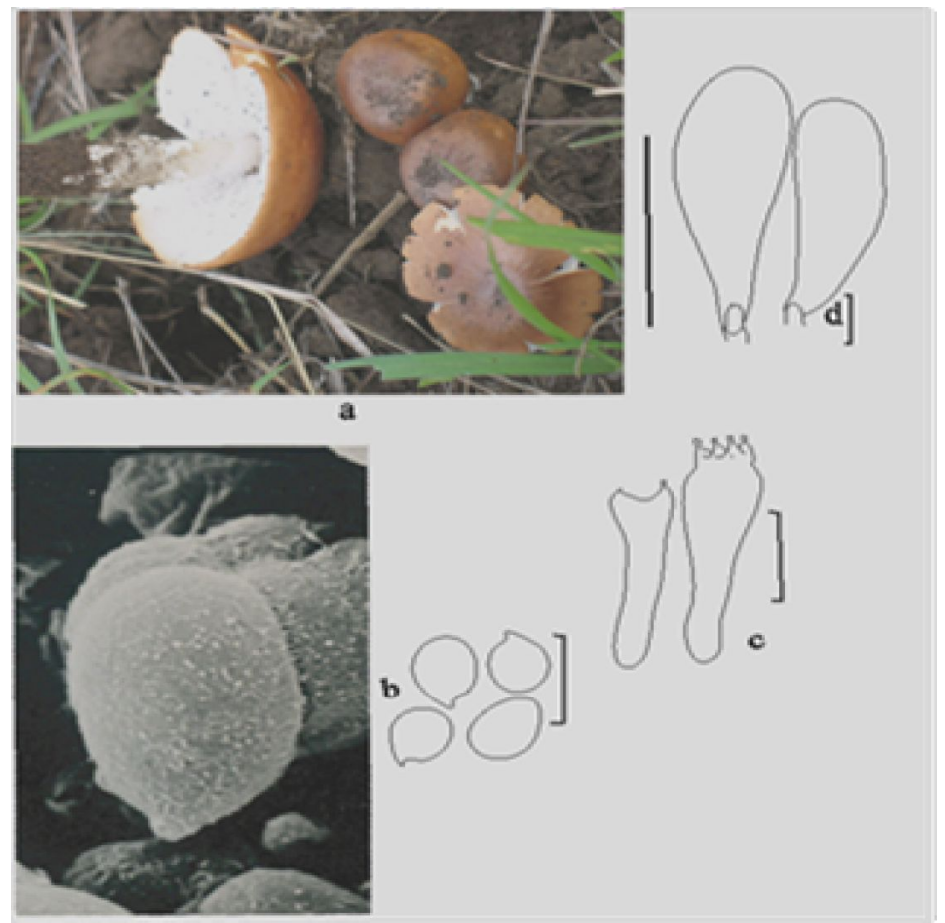

Figure 5. Termitomyces striatus (a) basidiome (b) basidiospore unsmooth surface revealed in SEM (c) basidia (d) cystidia

Comments: This is a medium sized mushroom and looks more close to T. aurantiacus. The SEM result showed the spore of this species with unique patches almost similar to those observed in T. aurantiacus (Figure 4b). These features strengthen the idea of the two species being con specific thus envisage more studies on these closely related species to ascertain their taxonomic status.

Specimen examined was from the National herbarium Cryptogamie Buyck PC 96119, from Zambia Mpongwe, DT 20010-49 from Loliondo Serengeti Mara region.

\subsubsection{Termitomyces sagittiformis Kalchbr \& Cke.}

Iconography:Vander Westhuisen and Eicker (1990: Figs 28-33).

Comments: It is a medium to rarely large sized mushroom distinguished in the field by its fusoid pseudorhiza. It grows on a termite mound more often in amore clay soil of the mound thus difficult to uproot until dug out with aid of the hoe. The SEM result of this specimen revealed the spore of this species being smooth emerging from four sterigmater of the same basidia

Specimen examined: Buyck PC 4572, from Zambia Road Mpongwe, DT 2009-56 from Mugumu, Mara region, DT 20010-48 from Serengeti National Park, Mara region 


\section{Macrothink}

\subsubsection{Termitomyces mammiformis Heim}

Iconography: Heim, (1977: Plate. 11, Fig. 2, e, f, g, h, and i)

Comments: Is a medium sized mushroom cap with demarcated and prominent blackish brown mammiform perforatorium. The species in the field is demarcated by its appendiculate annulus, cylindrical-conical perforatorium, which is black brown and the presence of noticeable velar squamules. The result of SEM study on this specie showed the spores being smooth emerging in fours from single basidia.

Specimen examined: Buyck PC 9267from Zambia Road Mpongwe-Ruanshya, DT 2009-34.

\subsubsection{Termitomyces titanicus Pegler \& Piearce (Fig.6)}

Iconography: Pegler and Piearce (1980: fig. 3 a-e); Piearce (1987: fig. 2 and 5); Piearce (1981: fig. 3); Buyck (1994: fig 22, 23 and 24)

Comments: The species is easily distinguished in the field by its enormous large sized basidiocarp of more than $40 \mathrm{~cm}$ diameter with a dark brown disk but lacking a prominent perforatorium. The noticeable small basidiospore sizes compared to other large sized species also demarcate $T$. titanicus. The SEM result on this species showed the spores to be smooth emerging four sterigmata of each basidia.

Specimen examined: Buyck PC 96006, from Burundi Cankunzo Province, DT 2009-22 from Serengeti National Park Mara region, DT 2009-46, DT 20011-12 from Kigoma.

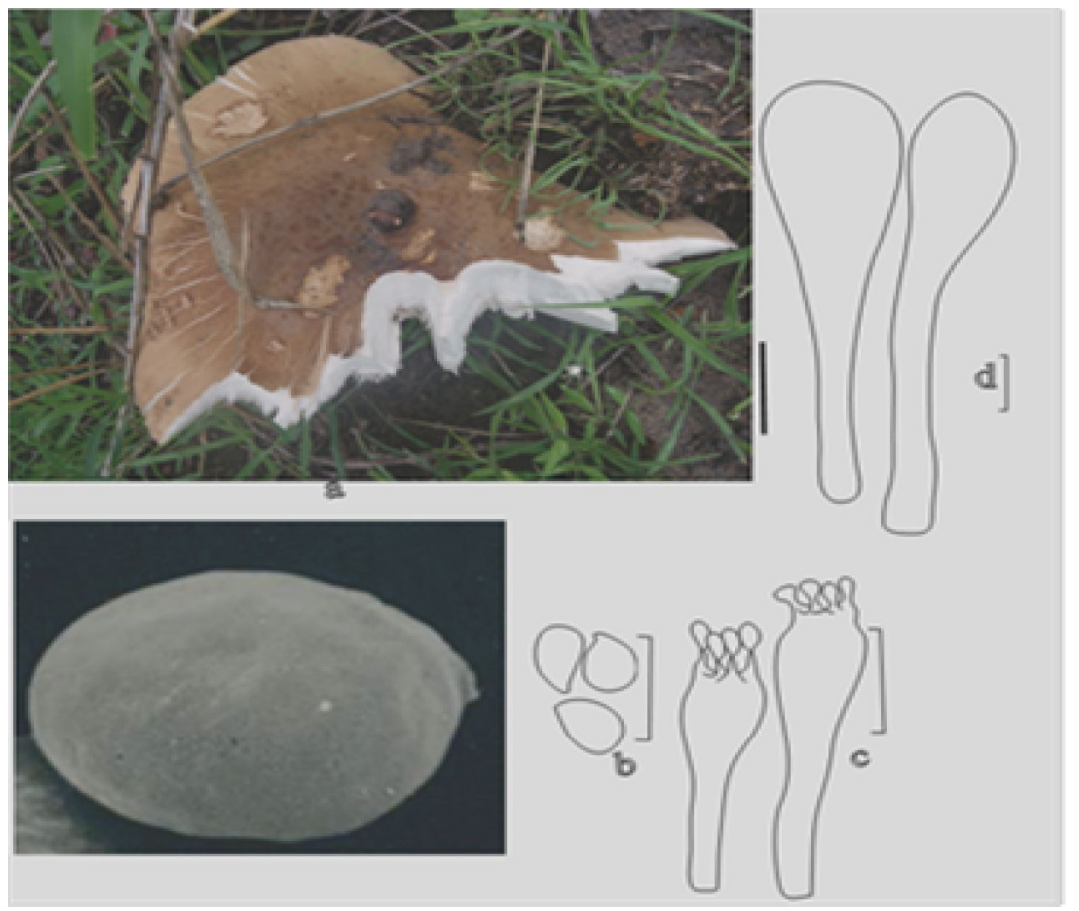

Figure 6. Termitomyces titanicus (a) basidiome (b) basidiospore smooth surface (c) basidia (d) cystidia 


\subsubsection{Termitomyces letestui (Pat.) R.Heim}

Iconography: Tibuhwa et al. (2010 : fig. 3 f); Härkönen et al. (2003: fig. 116)

Comments: This species is a large sized species easily recognized in the field by its striking sheathing annulus, large and fleshy cap which is cream at the surface becoming brown to sepia brown toward the distinct umbo. Unsmooth surface of the cap covered with felted tomentose which become finely squamulose toward the center and white gills with conspicuous pink tints demarcate the species. The SEM result showed it to have smooth tetra-sterigmate basidia.

Specimen examined: DT 2009-24 Mugumu, Mara region, DT 2009-32 Serengeti National Park Mara region, DT 2010-18 Loliondo, Mara region.

\subsubsection{Termitomyces eurhizus (Berk) R.Heim}

Iconography: Tibuhwa et al. (2010: fig. 3 e); Härkönen et al. (1995: fig. 42); (2003: fig. 115) Pegler (1977: fig. 62/2 a-e); Pegler and Rayner (1969: fig. 5/1 a-d)

Comments: This is a large sized species which in the field, is recognized by the brown, viscid, smooth pileal surface. In maturity in the first look it looks like T. umkowaani and $T$. globosus all having pseudorhiza with similar morphometry and colour which are all dark coloured widening to a certain point then narrowing unevenly to the point of attachment to the termite nests. T. eurrhizus is often noted by its very long thick pseudorhiza which may go up to two meters. However this character is not reliable since it depend on how deep the termitaria is located relative to the ground where the mushroom develop. Apart from the pdeudorhiza, the species has been also noted to morphologically resembling Termitomyces globosus by Härkönen et al. 2003, who suggested a taxonomic revision for the two taxa.

Specimen examined: DT 20010-18 Pwani, DT 2009-33 Serengeti National Park, Mara region.

\subsubsection{Termitomyces microcarpus (Berk \& Broome) Heim. (Fig.7)}

Iconography: Härkönen et al. (1995: fig. 42); Piearce (1987: figs 1 and 4); Vander Westhuisen \& Eicker, (1990: figs 1-6) ; Tibuhwa (2010: fig 3c). Pegler and Rayner (1969: fig. 2/3 a-d); (1977: fig. 59/1 a-d) 


\section{Ml Macrothink}

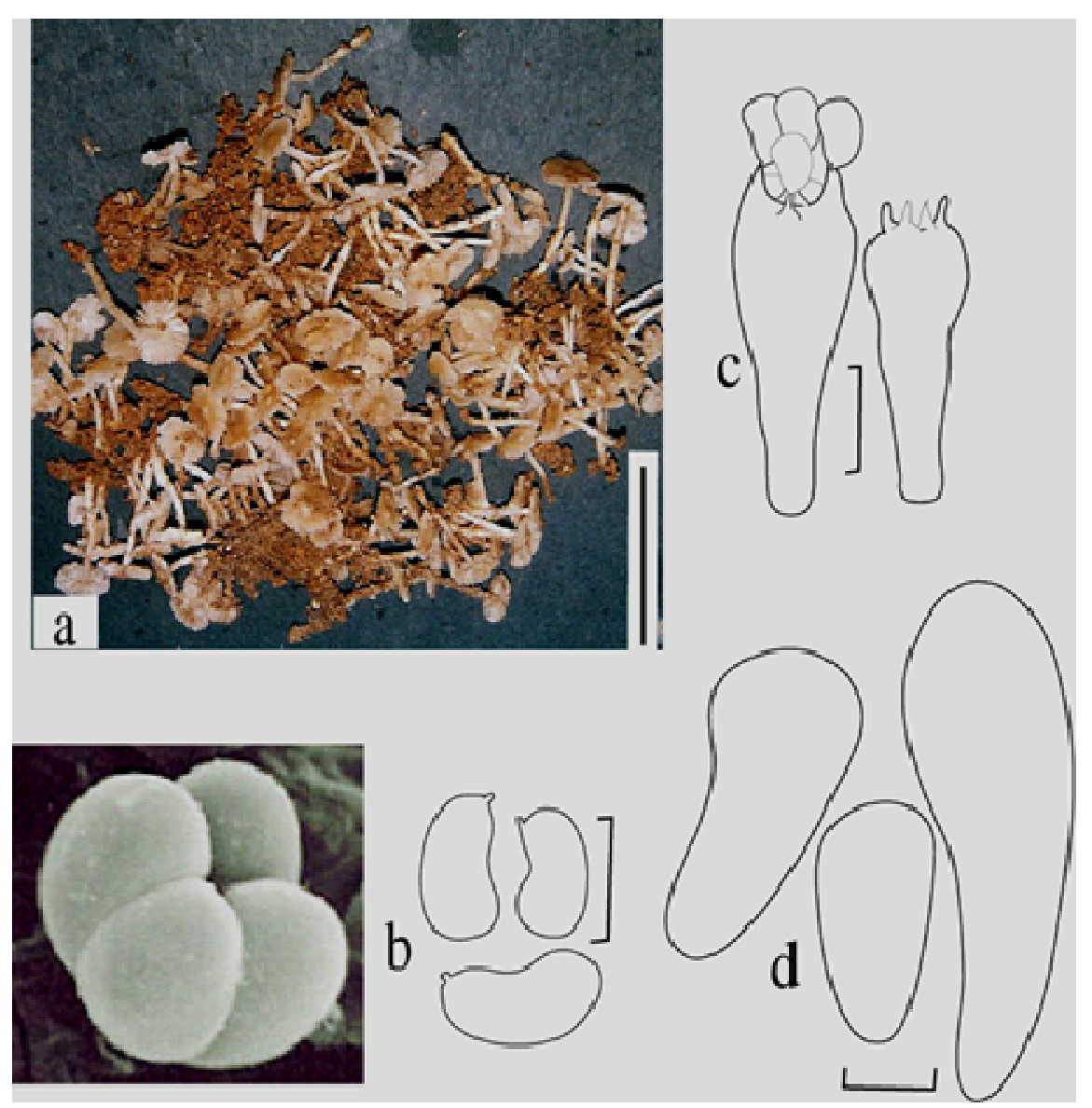

Figure 7. Termitomyces microcarpus (a) basidiome (b) basidiospore (c) basidia (d) cystidia

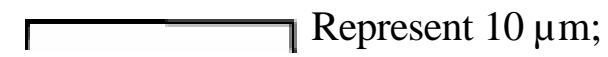

Represent $10 \mathrm{~cm}$

Comments: This species is easily recognized in the field by its very small size basidiome which is creamy white, lacking the pseudorhiza and occurrences in troops of hundreds. It is demarcated from its close T. badius which also lacks the pseudorhiza by its cream white colour unlike T. badius which is buffy brown. T. microcarpus had highest frequency of appearing out of the ten collected species, although, it is difficult to be found full grown in nature due to many competitors hunting it. Among its aggressive hunters includes monkeys, snakes, and human who often places local signs indicating booking on the mounds immediately as disused termite nests is cast by termites on the mounds.

Specimen examined: Tanzania Dar es Salaam Kinondoni - University of Dar es Salaam main campus near the post office D2000-4, behind Botany building D2000-8 (UDSM); Kinondoni - Madalla -wazohill D2001-14 (UDSM), D2004-19 Tabora and Buyck (PC) 96011, Buyck (PC) 96168 and Buyck (PC) 96171. 


\subsection{Cultural Studies}

\section{Termitomyces umkowaani and Termitomyces aurantiacus}

Growth: Growth rate was slow, colony diameter measured 10-18 $\mathrm{mm}$ after 5-8 weeks of growth. Lateral advancing zone was generally thinner than the rest of the mat and was often discrete easily recognized area with little or no differentiation thus presented little systematic informative data (see Fig. 8 c). Elevating zone had series of layers with typical aerial layer observed in old culture raised right to the limit of growth. Mat texture on both media was not uniform. Young portion of the mat were transparent while old parts as an outcome of the thickness and complexity of the interwoven mycelia were darker. Both isolates showed concentric circles of dense and light growth or zones exhibiting zonate-cottony type of mycelia growth (Stamets and Chilton, 1983). The zones were characteristic of natural changes in the age of the mycelium. The newest mycelia on the periphery of the culture were usually light and white in colour, while the more aged mycelium toward the centre of the culture were even darker and more differentiated and thus presented more systematic informative data.

For example in T. umkowaani the center becomes strongly pigmented with brown patches as that of the perforatorium of the fresh mature mushroom. Its mycelia also had very unique formations on their surface mat obviously distinct from the background mycelium. Mycelia aggregated into elevated forms forming cottony ball-like structures. These balls like structures become dark-brown on the surface of the stroma with age. Observation on oil immersion microscope old portion mycelia revealed enlargement of some cell for formation of conidia (see Fig. 8 f). Mycelia were cerebriform not easily separable from the agar. The culture of $T$. umkowaani differed from that of $T$. aurantiacus macro-morphologically by emitting strong mushroom odour, possession of dark-brown patches like ball aggregates on the surface of the stroma, as well as even more dark-brown center like its perforatorium ascending from the point of inoculums.

Somatic culture mat data have been rarely used in systematic studies of Termitomyces species. The major infringing factor is that they have low growth rate and sparingly available because up to date they have never been successfully domesticated and only few morphological differences exists in fungal cultures (Bother and Eicker 1991). For example, Bother and Eicker (1991) did not found any significant differences in micro-morphology of the 5 species 


\section{MInstitute ${ }^{\text {Mut }}$}
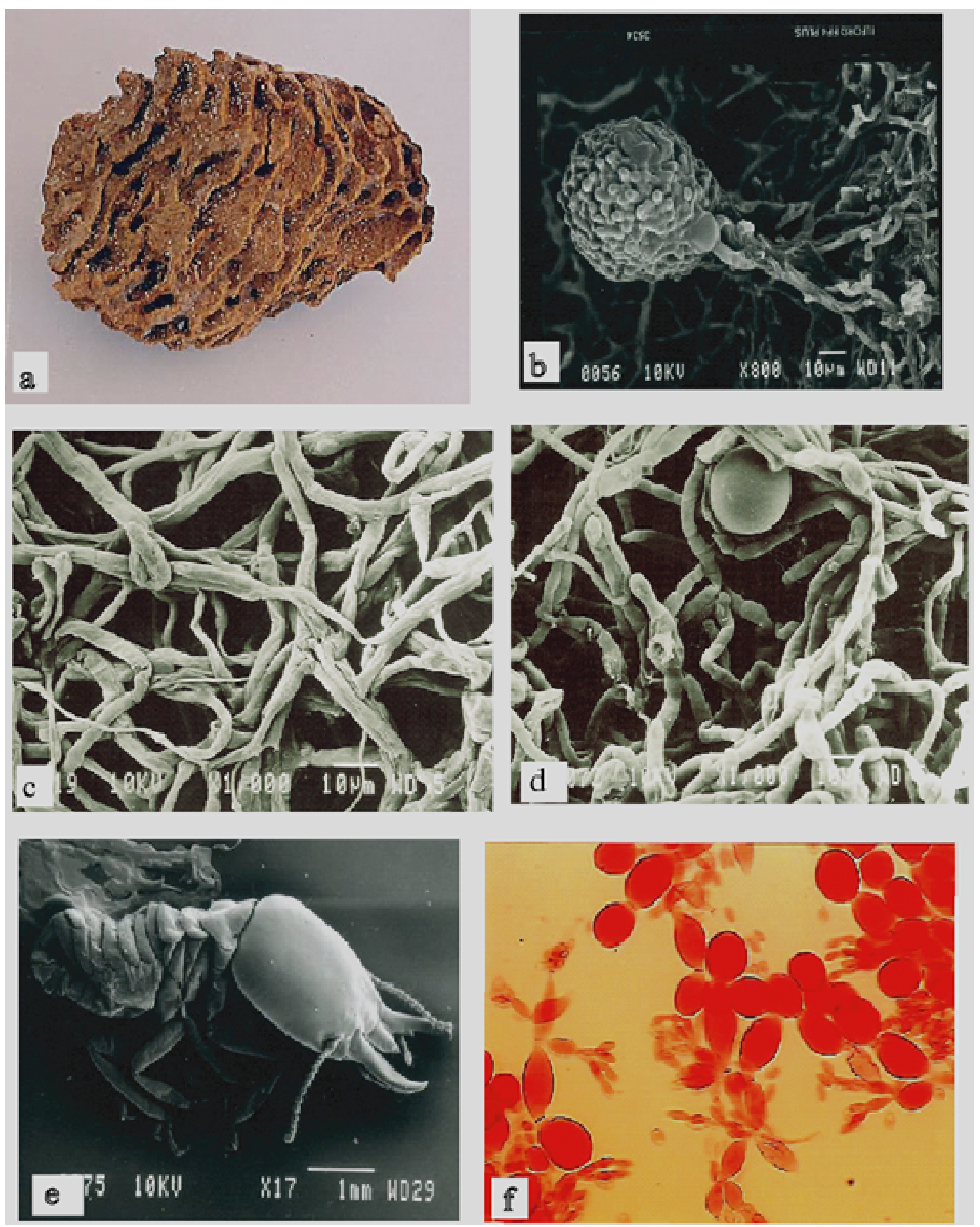

Figure 8. (a) Termite comb (b) sporodochia (c) young mycelia culture (d) Old mycelia culture (e) Odontotermes badius (f) sporulating conidia

of Termitomyces they studied from South Africa. Like wise in this study, there was no noticeable microscopic differentiation in both young and old mycelia of the two species although in old portion both species differentiated to form conidia, never the less, the results of this study support the utility of mycelia macro-morphology as good delimiting character.

In using MMEA media T. umkowaani showed an increased growth rate of up to $18 \mathrm{~mm}$ in 5 days as compared to $12 \mathrm{~mm}$ in Ghosh et al. (1978) media although T. aurantiacus did not show any differences. Both species failed to grow in Hagem Modess Medium for the reasons 
unknown to this study despite repeated efforts. Therefore this study recommends the use of MMEA media as well as Ghosh et al. (1978) media while did not support the use of Hagem Modess Medium for Termitomyces cultures.

\subsection{Key to the studied species}

1. Pseudorhiza absent, small species $<3 \mathrm{~cm}$ diameter, lacking veil, without or with little developed perforatorium.

T. microcarpus (Berk \& Broome) Heim

1. Pseudorhiza present, small to large species $>3 \mathrm{~cm}$ diameter, veil present/absent perforatorium well developed. .2

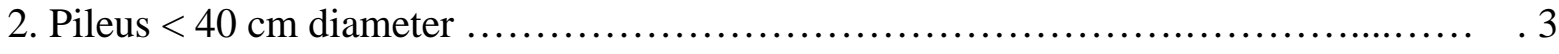

2. Pileus enormous large $>40 \mathrm{~cm}$ diameter ash grey to pale with brown- low blackish and conspicuous membranous annulus T. titanicus Pegler \& Piearce

3. Perforatorium strongly spiniform/ scrobiculate .4

3. Perforatorium conical to broadly conical and none scrobiculate .5

4. Basidiocarp not smooth, but covered with brownish striations and pustulate velar squamules, pileal surface pale brown throughout. T. mammiformis R.Heim

4. Basidiocarp smooth, blackish brown, pileus dark to brown paling grey at maturity T. clypeatus (Heim) Heim

5. Dull coloured basidiocarp. .6

5. Bright coloured basidiocarp .7

6. Pileus small to medium size, stipe Creamy-white extending to brown fusoid Pseudorhiza. T. sagittiformis Kalchbr \& Cke

6. Pileus medium to large, stipe non fusoid. .8

7. Pileus not exceeding $12 \mathrm{~cm}$ diameter, surface ochraceous brown T. striatus (Heim) 7.Pileus about 8-12 cm diameter, surface uniformly ochraceous orange. T. aurantiacus (Heim) Heim

8. Pileal surface viscid and brown T. eurrhizus (Berk) R.Heim

8. Pileal surface non viscid and non brown .9

9. Fleshy basidiocarp with striking conspicuous sheathing annulus and distinctive prominent umbo. T. letestui (Pat.) R.Heim

9. Fleshy basidiocarp with no conspicuous annulus and low broad umbo T. umkowaani Cke \& Mass. 


\section{Conclusion}

The unsmooth basidiospore which is contrary to the long known unifying characters of the termitophilic mushrooms 'smooth basidiospore' was revealed for the first time in this genus. This envisages a wider definition of the genus circumscription. Based on the culture data presented in this study, it appears that macromorphological culture characters provide taxonomic useful information in species delineation than do micromorphological characters. They thus, should be advocated for morphological taxonomic works. Further research, using molecular markers is needed on the two pairs of taxa $T$. aurantiacus vs $T$. striatus and $T$. umkowaani vs T. eurrhizus to ascertain their taxonomic status.

\section{Acknowledgements}

The author is grateful to the Germany embassy through DAAD project that sponsored early field work, the Association of Strengthening Agricultural Research in Eastern and Central Africa the (ASARECA) that sponsored sample collection in the Serengeti National Park, the Sida-SAREC project that sponsored data analysis at the National herbarium Cryptogamie (PC), the curators of the PC for their collections and the Department of Molecular Biology and Biotechnology and Department of Zoology of the University of Dar es Salaam for providing necessary facilities and assistance in termite identification respectively.

\section{References}

Aanen DK, Eggleton P, Rouland-Lefèvre C, Frøslev TG, Rosendah S, Boomsma JJ. (2002). The evolution of fungus-growing termites and their mutualistic fungal symbionts. Proceedings of the National Academy of Sciences of the United States of America 99: 14887-14892. http://dx.doi.org/10.1073/pnas.222313099.

Alasoadura SO. (1966). Studies in the higher fungi of Nigeria, Macrofungi associated with termites. Nova Hedwigia 11: 387-383

Batra LR, Batra SWT. (1979). Termite fungus mutualism. In Insect Fungus Symbiosis (ed. L.R. Batra), pp. 16-163. New York, U.S.A.: Jonh Willey and Sons.

Bels, PJ, Pataragetvit S. (1982). Edible mushrooms in Thailand cultivated by Termites Chinese University Press.

Bother WJ, Eicker A. (1991). Cultural studies on the genus Termitomyces in South Africa. Macro-and Microscopic characters of Basidiome contexst cultures. Mycological Research. 95 (4): 435-443. Printed in Britain. http://dx.doi.org/10.1016/S0953-7562(09)80843-5.

Buxton RD. (1981). Termites and the turnover of dead wood in an arid tropical environment. Oecologia 51:379-384. http://dx.doi.org/10.1007/BF00540909.

Buyck B. (1994). Ubwoba: Les champignons comestibles de I'Ouest du Burundi. Administ. generale de la cooperation au develppement Rue du Trone, 4-1050 Bruxelles. Publication Agricole No 34. 
Buyck B, Nzigidahera B. (1995). Ethnomycological notes from western Burundi. Belgian Journal of Botany 128:131-138.

Chang ST, Quimio TH. (1982). Tropical Mushrooms Biological Nature and Cultivation Methods. The Chinese University Press of Hong Kong. pp. 445-460.

Collins NM. (1983). The utilization of nitrogen resources by termites (Isoptera), In. Lee JA, McNeill S, Rorison IH (ed.), Nitrogen as an ecological factor, p. 381-412. Blackwell Scientific, Oxford, United Kingdom.

Frøslev TG, Aanen DK, Læssøe T, Rosendahl S. (2003). Phylogenetic relationships of Termitomyces and related taxa. Mycological Research 107: 1277-1286. http://dx.doi.org/10.1017/S0953756203008670.

Ghosh S, Paweletz N, Ghosh I. (1978). Mitotic asynchrony of multinucleate cells in tissue culture. Chromosoma 65 (4) 293-300. http://dx.doi.org/10.1007/BF00286409.

Gómes LD. (1995). Una nueva specie neotropical de Termitomyces (Agricales: Termitomycetaceae). Revista de biologia Tropical 42 : 439-451.

Grassé PP, Noirot C. (1958). Le meule des termites champignonnistes et sa signification symbiotique. Ann. Sci. Nat. Zool. Biol. Anim. 20:113-128.

Härkönen MT, Saarimaki, Mwasumbi L. (1995). Edible mushroom of Tanzania. KARSTENIA, 35: Suppl., 92pp.

Härkönen MT, Niemelä T, Mwasumbi L. (2003). Tanzanian Mushrooms Edible, harmful and other fungi. Botanical Museum Finnish Museum of Natural History, 200 pp.

Heim R. (1942). Nouvelles e'tudes descriptives sur les Agarics termitophiles d'Afrique tropicale. Archives du Muse'um National d'Histoire Naturelle se'r. 6, 18, 107-166.

Heim R. (1977). Termites et Champignons.Les termitophiles d'Afrique Noire at d'Asie Meridionale. Paris, France: Societe Novelle des Edition. 205 pp. Boubee, Paris.

Hyodo F, Tayasu I, Inoue T, Azuma J-I, Kudo T, Abe T. (2003). Differential role of symbiotic fungi in lignin degradation and food provision for fungus-growing termites (Macrotermitinae: Isoptera). Functional Ecologist. 17:186-193.

http://dx.doi.org/10.1046/j.1365-2435.2003.00718.x.

Martin MM, Martin JS. (1978). Cellulose digestion in the midgut of the fungus-growing termites Macrotermes natalensis: the role of acquired digestive enzymes. Science 199:1453-1455. http://dx.doi.org/10.1126/science.199.4336.1453.

Matsumoto T. (1976). The role of termites in an equatorial rain forest ecosystem of west Malaysia. Population density, biomass, carbon, nitrogen and calorific content and respiration rate. Oecologia 22:153-178. http://dx.doi.org/10.1007/BF00344714.

Moncalvo JM, Lutzoni FM, Rehner SA, Johnson J, Vilgalys R. (2000). Phylogenetic relationships of agaric fungi based on nuclear large subunit ribosomal DNA sequences. Systematic Biology 49: 278-305. http://dx.doi.org/10.1093/sysbio/49.2.278. 
Morris B. (1986). Notes on the genus Termitomyces Heim in Malawi. Society of Malawi Journal $39,40-49$.

Natarajan NK. (1979). South Indian Agaricales v:Termitomyces heimii. Mycologia, 71, 853-855. http://dx.doi.org/10.2307/3759201.

Olila D, Kyeyune G, Kabasa JD, Kisovi 1, Munishi PKT. (2007). Assessment of Potential for Domestication of Termitomyces microcarpus: An indigenous Edible and Medicinal Mushroom from Lake Victoria Basin. Agricultural Journal, 2: 627-631.

http://medwelljournals.com/abstract/?doi=aj.2007.627.631.

Otieno NC. (1964). Contributions to knowledge of Termite fungi in East Africa. Proceedings of the East African Academy 11, 108-120.

Pegler DN. (1977). A preliminary Agaric flora of East Africa. Kew Bull. Add. Ser 6: 1-615. London. HMSO.

Pegler DN, Piearce GD. (1980). The edible mushrooms of Zambia Kew Bulletin 35: 475-491. http://www.jstor.org/stable/4110017.

Pegler DN, Rayner RW. (1969). A contribution to the Agaric flora of Kenya. Kew Bulletin 23: 347-412. http://dx.doi.org/10.2307/4117177.

Pegler DN, Van haecke M. (1994). Termitomyces of Southeast Asia. Kew Bulletin. U.K.

Petch T. (1913). Termite fungi: a résumé. Ann Roy Bot Gard (Peradeniya) 5:303-341.

Piearce GD. (1987). The genus Termitomyces in Zambia. The mycologist 1: 111-116. http://dx.doi.org/10.1016/S0269-915X(87)80080-0.

Rohrmann GF. (1978). The origin, structure and nutritional importance of the comb in two species of Macrotermitinae. Pedobiologia 18:89-98.

Rouland-Lefevre C, Diouf MN, Brauman A, Neyra M. (2002). Phylogenetic relationships in Termitomyces of ITS: a first approach to elucidate the evolutionary history of the symbiosis between fungus-growing termites and their fungi. Molecular Phylogenetics \& Evolution 22: 423-429. http://dx.doi.org/10.1006/mpev.2001.1071.

Rouland-Lefèvre C. (2000). Symbiosis with fungi, In Abe T, Bignell DE, Higashi M (ed.), Termites: evolution, society, symbioses, ecology, p. 289-306. Kluwer Academic Publishers, Dordrecht, The Netherlands.

Sands WA. (1960). The initiation of fungus comb colonies construction in the Laboratory of Ancistrotermes guineensis (Silvestri). Insectes Soc. 7:251-263.

http://dx.doi.org/10.1007/BF02224496.

Sing'er R. (1986). The Agaricales in Morden taxonomy, 980pp., Germany Konigstein.

Stamets P, Chilton J. (1983). The Mushroom Cultivator: A Practical Guide to Growing Mushrooms at Home. Agarikon Press, Washington.

Tibuhwa DD, Buyck B, Kivaisi AK, Tibell L. (2008). Cantharellus fistulosus sp. nov. from 


\section{Macrothink

Tanzania. Journal of mycologie 29: 129-135.

Tibuhwa DD, Kivaisi AK, Magingo FFS. (2010). Utility of the macro-micromorphological characteristics used in classifying the species of Termitomyces. Tanzania Journal of Science,36: 3-46. http://ajol.info/index.php/tjs/article/view/73538/62452.

Tibuhwa DD, Nyawira M, Masiga CW, Mugoya C, Muchai M. (2011). An inventory of Macro-fungi and their Diversity in the Serengeti-Masai Mara ecosystem, Tanzania and Kenya. Journal of Biological Sciences, 11: 399-410. ttp://scialert.net/abstract/?doi=jbs.2011.399.410.

Vander Westhuisen GCA, Eicker A. (1990). Species of Termitomyces in South Africa Mycological Research, 94: 923-937.

Wood TG, Thomas R J. (1989). The mutualistic association between Macrotermitinae and Termitomyces, p. 69-92. In Wilding N, Collins N M, Hammond PM, Webber JF (ed.), Insect-fungus interaction. Academic Press, London, United Kingdom.

Yamada A, Inoue T, Wiwatwitaya D, Ohkuma M, Kudo T, Abe T, Sugimoto A. (2005). Carbon mineralization by termites in tropical forests, with emphasis on fungus-combs. Ecological Research, 20:453-460. http://dx.doi.org/10.1007/s11284-005-0062-9.

Zhang ZF, Ruan XY. (1986). A new species Termitomyces macrocarpus Zhang and Ruan sp.nov. Edible Fungi, 5, 10-13.

\section{Copyright Disclaimer}

Copyright reserved by the author(s).

This article is an open-access article distributed under the terms and conditions of the Creative Commons Attribution license (http://creativecommons.org/licenses/by/3.0/). 